\title{
Controlled-release of Bacillus thurigiensis formulations encapsulated in light-resistant colloidosomal microcapsules for the management of lepidopteran pests of Brassica crops
}

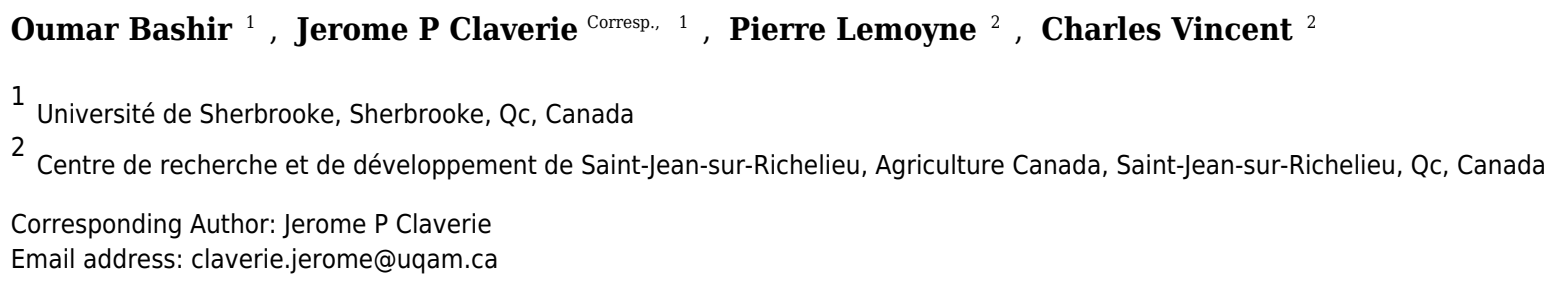

Bacillus thuringiensis ( $B . t$.) based formulations have been widely used to control lepidopteran pests in agriculture and forestry. One of their weaknesses is their short residual activity when sprayed in the field. Using Pickering emulsions, mixtures of spores and crystals from three $B$. t. serovars were successfully encapsulated in colloïdosomal microparticles $(50 \mu \mathrm{m})$ using innocuous chemicals (acrylic particles, sunflower oil, iron oxide nanoparticles, ethanol and water). A pH trigger mechanism was incorporated within the particles so that $B$. $t$. release occurred only at $\mathrm{pH}>8.5$ which corresponds to the midgut $\mathrm{pH}$ of the target pests. Laboratory assays performed on Trichoplusia ni larvae demonstrated that the microencapsulation process did not impair $B$. $t$ bioactivity. The best formulations were field-tested on three key lepidopteran pests that attack Brassica crops, i.e., the imported cabbageworm, the cabbage looper and the diamondback moth. After 12 days, the mean number of larvae was significantly lower in microencapsulated formulations than in a commercial $B$. $t$. formulation, and the effect of microencapsulated formulations was comparable to a chemical pesticide (lambda-cyhalothrin). Therefore, colloïdosomal microcapsule formulations successfully extend the bioactivity of $B$. $t$. for the management of lepidopteran pests of Brassica crops. 
1 Controlled-release of Bacillus thurigiensis formulations encapsulated in light-

2

\section{resistant colloidosomal microcapsules for the management of lepidopteran}

\section{pests of Brassica crops}

Oumar Bashir ${ }^{\mathrm{a}}$, Jerome P. Claverie $\mathrm{a}^{\mathrm{*} \$}$, Pierre Lemoyne ${ }^{\mathrm{b}}$, Charles Vincent $\mathrm{b}^{\text {***}}$

a. Département de Chimie, Université de Sherbrooke, 2500, Blvd de l'Université, Sherbrooke, Qc, J1K2R1 Canada

* Tel.: + 1819821 7246, E-mail: jerome.claverie@usherbrooke.ca

\$ this work was performed at the Université du Québec à Montréal (UQAM)

b. Saint-Jean-sur-Richelieu Research and Development Centre, Agriculture Agri-Food Canada 430 Gouin Blvd., Saint-Jean-sur-Richelieu, QC, Canada J3B 3E6

** Tel.: + 1450346 4494, E-mail: charles.vincent@agr.gc.ca

\section{Abstract}

Bacillus thuringiensis (B. t.) based formulations have been widely used to control lepidopteran pests in agriculture and forestry. One of their weaknesses is their short residual activity when sprayed in the field. Using Pickering emulsions, mixtures of spores and crystals from three $B$. $t$. serovars were successfully encapsulated in colloïdosomal microparticles $(50 \mu \mathrm{m})$ using innocuous chemicals (acrylic particles, sunflower oil, iron oxide nanoparticles, ethanol and water). A $\mathrm{pH}$ trigger mechanism was incorporated within the particles so that $B$. $t$. release occurred only at $\mathrm{pH}>8.5$ which corresponds to the midgut $\mathrm{pH}$ of the target pests. Laboratory assays performed on Trichoplusia ni larvae demonstrated that the microencapsulation process did not impair $B . t$ bioactivity. The best formulations were field-tested on three key lepidopteran pests that attack Brassica crops, i.e., the imported cabbageworm, the cabbage looper and the 
28 diamondback moth. After 12 days, the mean number of larvae was significantly lower in

29 microencapsulated formulations than in a commercial B.t. formulation, and the effect of 30 microencapsulated formulations was comparable to a chemical pesticide (lambda-cyhalothrin).

31 Therefore, colloïdosomal microcapsule formulations successfully extend the bioactivity of B.t.

32 for the management of lepidopteran pests of Brassica crops. 


\section{INTRODUCTION}

Bacillus thuringiensis (B. t.) is an aerobic bacterium which upon sporulation forms a parasporal inclusion body, the crystal. The latter is made of Cry proteins which often exhibit insecticidal activities [1]. Worldwide, $B$. $t$. based formulations account for ca. $50 \%$ of the market for sprayable biopesticides [2]. One weakness of such formulations is their short residual activity in the field, resulting from UV light-induced degradation of the toxin [3]. This shortcoming can be addressed by developing innovative formulations which screen or reflect UV light.

The formulation of a pesticide is of paramount importance to optimize its efficacy. Ideally, the formulation should provide maximal effect to the active ingredient, while exerting minimal unintended negative effects on non-target organisms. Knowles [4] outlined the main factors to take into account in the formulation of agrochemicals. Briefly, these factors are the physico-chemical properties of the active principle, its biological activity and mode of action, the method of application, the safety in use, the formulation cost, and the market preferences. Microencapsulation has recently attracted considerable attention because of the possibility of controlling the release rate of an active component. Microencapsulated formulations are now used for a variety of applications, such as pharmaceutical [5], biotechnological [6,7] and agricultural ones [8,9]. However, most of the methods used to fabricate microcapsules for biopesticides require environmentally unfriendly conditions, such as the use of organic solvents and monomers or elevated temperatures. As mentioned by Boyetchko et al. [10] and Brar et al.

53 [11], the microencapsulation of biopesticides based on living organisms (e.g. bacteria, fungi, 4 viruses) is often accompanied by a loss of bioactivity. In their review on nanoparticle systems for the delivery of pesticides [12], De et al. only mentioned inert active ingredients (i.e. chemicals or proteins). Behle et al.[13] developed a formulation whereby a hydrophobic fungus (Beauvaria 
57 bassiana) and a hydrophilic baculovirus (Pieris rapae granulovirus) were encapsulated in a UV-

58 protecting microcapsule. Likewise, when sprayed on apple trees in an orchard, DiPel (a commercial B. t. serovar kurstaki formulation) and a bio-encapsulated formulation caused significant mortality to oblique banded leafroller (Choristoneura rosaceana Harris) larvae respectively up to 3 and 14 days after treatments [14].

We here present a novel B. $t$. encapsulation system based on the fabrication of Pickering emulsions. Pickering emulsions are stabilized by interfacial nanoparticles. For example, in a water-in-oil (w/o) Pickering emulsion, micron-size droplets of water are dispersed in a continuous oil phase and nanoparticles are located at the interface between the water and oil phases. Depending on their surface tension, these nanoparticles can stabilize the emulsion in the colloidal sense. They prevent the fusion of water droplets which eventually leads to phase separation. Velev et al.[15,16] were the first to demonstrate that Pickering emulsions can be transformed into microcapsules when the interfacial nanoparticles are either linked or fused together to form a continuous wall (Figure 1). This step, usually referred as locking, can be achieved via a variety of techniques, such as chemical cross-linking [17], in situ polymerization [18], thermal softening [19] and solvent-instability of the particle [20-22]. When nanoparticles are polymeric in nature, a continuous wall can thus be formed around the aqueous droplet, leading to the formation of a microcapsule called colloïdosome by analogy with liposomes which are phospholipid stabilized aqueous vesicles.

In this work, we prepared novel $\mathrm{pH}$-sensitive colloïdosomal microparticles containing $B . t$. parasporal crystals (i.e. mixtures of spores and crystals) using a solvent-instability locking mechanism recently developed by Routh et al [22]. These microparticles were designed so that

1) they maintained the bioactivity of $B . t . ; 2$ ) they could release $B . t$. parasporal crystals in the 
80 midgut of a lepidopteran larvae, notably when $\mathrm{pH}>8$; 3) they were opaque in order to prevent

81 light-induced damage of the B. t. spore; and 4) they could be dispersed in water in order to form

82 a free-flowing non-viscous aqueous formulation.

83 Four key lepidopteran pests attack Brassica crops (i.e. broccoli, Brussel sprouts, cabbage

84 and cauliflower) in Canada: the imported cabbageworm (Artogeia rapae (L.)), the cabbage

85 looper (Trichoplusia ni, T. ni (Hübner)), the diamondback moth (Plutella xylostella (L.)) and the

86 alfalfa looper (Autographa californica Spreyer) [23]. Here, we document the development of a

87 microencapsulated formulation of three bioactive B. t. serovars. The efficiency of these

88 formulations was first assessed through a series of laboratory assays on cabbage looper larvae,

89 and, in a second step, these formulations were tested in a cabbage field against aforementioned

90 Brassica pests.

91 

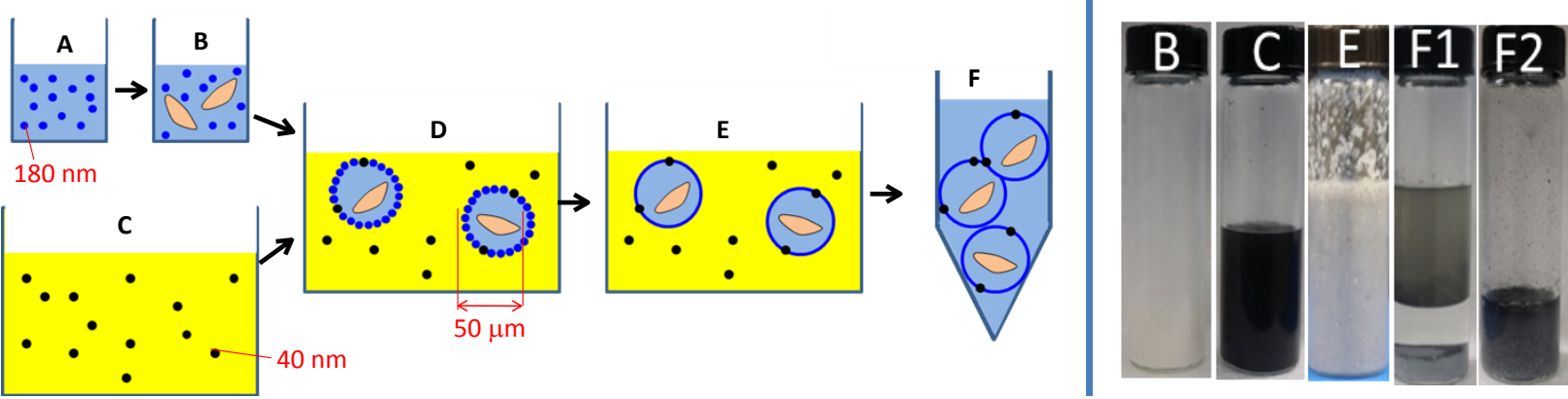

Figure 1. Left: Schematic representation of the preparation process for the $B$. $t$. strains encapsulated within the colloïdosomal microcapsules. A) latex particles of poly(butylmethacrylate-co-methacrylic acid) in water. B) latex $+B$. $t$. spores and crystals C) sunflower oil $+\mathrm{Fe}_{3} \mathrm{O}_{4}$ nanoparticles. D) W/O Pickering emulsion. E) Locking of the microcapsules upon addition of ethanol. F) Collection of the microcapsules by centrifugation. In the actual process, ethanol is added at the same time as the oil phase, and therefore, the Pickering emulsion (D) is not isolated. Right: Representative pictures of the various steps of the Pickering process. Step F1 corresponds to the microcapsules immediately after centrifugation. The microcapsules are at the bottom of the vial, and are surmounted by an aqueous solution and then by the oil solution. Once the oil is separated, the redispersed microcapsules appear as a free flowing powder in water (F2). 


\section{MATERIALS AND METHODS}

109

110

111

112

113

114

115

116

117

\subsection{B. $t$. culture and preparation}

The bacterial strains Bacillus thuringiensis serovar kurstaki HD1, Bacillus thuringiensis serovar aizawai, Bacillus thuringiensis serovar tolworthi and Bacillus thuringiensis serovar 407 [24] were grown in CCY medium [25] and incubated in a rotary shaker (200 rpm) at $30^{\circ} \mathrm{C}$ for 3 days. All $B$.t. cultures were centrifuged at $8000 \mathrm{rpm}$ for $15 \mathrm{~min}$ at $4^{\circ} \mathrm{C}$. The pellets, composed essentially of spores and parasporal inclusion bodies mixture, were washed with sterilized bidistilled water $\left(\mathrm{ddH}_{2} 0\right)$ and precipitated with 5\% lactose weight/weight and acetone to obtain a dry and fine powder soluble in water [26]. After microscopic examination, more than $90 \%$ of the cells were lyzed.

\subsection{Preparation of latex particles of poly(butylmethacrylate-co-methacrylic acid)}

In a $250 \mathrm{~mL}$ glass-jacketed reactor was added $100 \mathrm{~mL}$ of nanopure water $(\sigma=18 \mathrm{M} \Omega / \mathrm{cm})$, $10 \mathrm{~g}$ of butyl methacrylate (70 mmoL, purified over basic alumina), $5 \mathrm{~g}$ of methacrylic acid (59 mmoL, purified over silica), $0.5 \mathrm{~g}$ of sodium dodecyl sulfate as stabilizer and $0.25 \mathrm{~g}$ of potassium persulfate as initiator. This mixture was mechanically stirred at $400 \mathrm{rpm}$ and degassed by bubbling nitrogen for 20 minutes. It was then heated to $80^{\circ} \mathrm{C}$ while keeping a nitrogen blanket above the liquid phase in order to avoid $\mathrm{O}_{2}$ introduction. After 12 hours of reaction time, a latex devoid of floc was obtained. The particles were readily soluble in alkaline environment $(\mathrm{pH}=$ 8.5). The latex solid content, as determined gravimetrically, was $12 \%$.

\subsection{Formation of the colloïdosome}

The preparation process is outlined in Figure 1 and representative pictures are presented in Figure 2. In a first incubation tube was added $20 \mathrm{~mL}$ of commercial sunflower oil, $10 \mathrm{mg}$ of 
$130 \mathrm{Fe}_{3} \mathrm{O}_{4}$ nanoparticles $($ size $=40 \mathrm{~nm}$, see supporting data, measured by dynamic light scattering in 131 water) and $2 \mathrm{~mL}$ of absolute ethanol (C, Figure 1). The mixture was processed with a vortex

132 mixer for 1 minute. In a separate tube, $1 \mathrm{~g}$ of $B . t$. kurstaki strain (under the form of a dry 133 powder) was added to $5 \mathrm{~mL}$ of the latex prepared in $2.2(\mathrm{~B}$, Figure 1$)$. Then, $5 \mathrm{~mL}$ of nanopure 134 water containing $146 \mathrm{mg}$ of $\mathrm{NaCl}$ was added and the mixture was stirred with a vortex mixer for 135 a minute. The contents of both vials were added to each other and were mixed again with a 136 vortex mixer for one minute (E1, Figure 1). Then, the mixture was centrifuged at $5000 \mathrm{rpm}$ (E2,

137 Figure 1) in order to separate the dark grey colloidosomal microcapsules from the supernatant oil 138 phase (F, Figure 1). In order not to break the microcapsules, centrifugation was never performed 139 for more than 5 minutes, but the process was repeated until oil was no longer observed on top of 140 the microcapsules.

\subsection{Characterization by atomic force microscopy (AFM)}

The suspension containing the microcapsules was diluted 100 times with water. A drop of the diluted suspension was applied on a mica plate and was left to dry in air. The plate was analyzed on a Veeco Dimension 5000 microscope equipped with Nanoscope V controller

145 (Bruker/ Veeco, Santa Barbara, CA, USA). All images were taken at room temperature using tapping mode and analysed with the Gwyddion software.

\subsection{Insect rearing, laboratory assays, field trial and persistence of formulations}

Rearing. A cabbage looper colony was maintained at Agriculture and Agri-Food Canada at $25^{\circ} \mathrm{C}, 70 \% \mathrm{R} . \mathrm{H}$., and $16 \mathrm{~h}$ photophase $/ 8 \mathrm{~h}$ scotophase. Larvae were fed on solidified diet prepared according to Shorey and Hale [27].

Laboratory assays. Liquid diet was poured in stainless steel molds (18 x 9 x $9 \mathrm{~cm})$. Upon solidification of the diet, $1 \mathrm{~cm}$ thick slices were cut and put on a glass plate. A plastic grid was 
153 enforced in the diet, thus enclosing 50 cells $(1 \mathrm{x} 1 \mathrm{~cm})$ with diet in the bottom half. From a

154 suspension containing B. t. (microencapsulated or not) at a concentration of $1 \mathrm{mg} / \mathrm{ml}$, a $50 \mu 1$

155 aliquot was pipetted on the surface of the diet of each cell. It was allowed to dry for $1 \mathrm{~h}$. One first

156 instar cabbage looper larva was put on the treated diet of each cell. The preparations were held at $15725^{\circ} \mathrm{C}, 70 \%$ R.H., and $16 \mathrm{~h}$ photophase/ $8 \mathrm{~h}$ scotophase for 7 days. The negative controls consisted 158 of water, iron nanoparticles, B. $t$. serovar 407 (a Cry- B. $t$. serovar) and lactose powder. The 159 positive control was B. t. kurstaki HD1. Larval mortality was assessed after 7 days.

160 Persistence of $\boldsymbol{B}$. $\boldsymbol{t}$. formulations. Cabbage seedlings (8-9 leaves) grown in pots in 161 greenhouses were brought to a field at the Experimental Farm of Agriculture and Agri-Food 162 Canada in L'Acadie (45,29972 N, 73,34972 W), Quebec, Canada. They were randomly assigned 163 to one of six treatments and sprayed accordingly with a handheld sprayer until run-off on 29 July 1642015 (=day 0). The treatments were: 1) no treatment (negative control 1); 2) microencapsulated 165 Bacillus thuringiensis serovar 407 (cry -) (negative control 2); 3) microencapsulated Bacillus 166 thuringiensis serovar kurstaki HD-1; 4) microencapsulated Bacillus thuringiensis serovar 167 aizawai; 5) microencapsulated Bacillus thuringiensis serovar tolworthi; 6) Bioprotec CAF 168 (commercial Bt-based biopesticide, 8.2\% dry weight) (AEF Global, Lévis, Canada) (positive control 1); The formulations were applied at a concentration of $1 \mathrm{~g}$ of $B . t$. (not formulated)/L. 170 Bioprotec CAF was applied at a rate of $2.8 \mathrm{~L} /$ ha. Thus, 72 potted plants were assigned as 171 follows: 6 treatments x 6 durations in the field x 2 plants per combination treatment/duration. 172 Immediately after the sprays, two plants were selected for each treatment and were brought back 173 to the laboratory for assays (= day 0$)$. Once the sprays dried, the pots containing the remaining 174 plants were buried in the soil, leaving the plants exposed to normal climatic conditions. 
At day 1, 2, 3, 6 and 9 after application, ten leaves were picked from two plants randomly selected in each treatment and 4 discs were punched out of each leaf. These discs were deposited in $9 \mathrm{~cm}$ Petri dishes, and 10 neonate $T$. $n i$ from a mass rearing were introduced in the dish for a 178 total of $2 \times 50$ larvae per treatment. Larvae were allowed to feed on the discs for $24 \mathrm{~h}$, and then transferred onto untreated artificial diet [27]. Larvae were maintained at $25 \pm 1^{\circ} \mathrm{C}, 60-70 \%$ R.H. and L:D 16:8 (Sanyo model MLR-351H,Osaka, Japan). Larval mortality was assessed 5 days after transfer to artificial diet.

Field trial. The field trial was done a few meters away from the persistence trials. Cabbage seedlings (cv. "Lennox") were transplanted at 3-4 true leaf stage in a Saint-Blaise clay loam on 30 June 2014 . They were spaced $47 \mathrm{~cm}$ apart in the rows and the rows were spaced $80 \mathrm{~cm}$ apart.

The experimental layout was a complete randomized block with four replicates. Each block had 28 rows and covered $257.6 \mathrm{~m}^{2}(11.5 \times 22.4 \mathrm{~m})$. It was subdivided into 7 experimental units consisting of 4 contiguous rows and each corresponded to a treatment randomly assigned within a given block. Blocks were spaced by a non-cultivated $5 \mathrm{~m}$ wide strip.

The six treatments described above were conducted and a seventh chemical pesticide treatment (positive control 2) was conducted using the insecticide Matador® (Lambdacyhalothrin, Syngenta Canada Inc., Guelph, Canada), applied at $83 \mathrm{~mL} / \mathrm{ha}$. The treatments were applied on 28 August and 5 September 2014 and only the two central rows of each experimental unit were sprayed in order to leave a buffer between treated rows.

The B. $t$. serovars were prepared as described above. The powders were formulated as described in Section 2.2. The surfactant Tween $80^{\circledR}$ was added to the tank mix at a concentration of $0.1 \% \mathrm{v} / \mathrm{v}$. The treatments were applied at a rate of $500 \mathrm{~L} /$ ha with a SOLO backpack sprayer 
197 (model 425), at a maximal pressure of 200 kiloPascal (2 bars) (SOLO, Newport News, VA, 198 USA). The mean flow was $1.28 \mathrm{~L} / \mathrm{min}$.

199 One day before insecticidal sprays, i.e. 27 August 2014, larval infestations of the imported 200 cabbageworm (P. rapae), the diamondback moth (P. xylostella), and the cabbage looper (T. ni), 201 were determined. Weekly counts of larvae on seven randomly selected plants in each 202 experimental unit were made to evaluate the larval abundance and to determine the efficacy of 203 treatments until 9 September 2014.

204 Temperature, precipitation and solar radiation were taken from a weather station on the 205 experimental farm located ca. $600 \mathrm{~m}$ from the efficacy trial. Relevant data was extracted form a

206

207

208

209

210

211

212

213

214

215

216

217

218

219

database with the software CIPRA [28].

Insect counts of the field trial and arcsin-transformed mortality data of the persistence assays were analyzed using an ANOVA treatment followed by a Tukey HSD test for post-hoc comparisons of means. All statistical analyses were done with XLSTAT Version 2011.5.01 (Addinsoft, New York, NY, USA).

\section{RESULTS AND DISCUSSION}

\subsection{Preparation of the colloidosomes}

The preparation of the colloidosomal microcapsules began with the preparation of a $\mathrm{pH}$ sensitive latex of poly(butylmethacrylate-co-methacrylic acid) (polyA) by an emulsion polymerization process (Figure 1A). The latex was constituted of polymer particles with a hydrodynamic diameter of $143 \mathrm{~nm}$ as measured by dynamic light scattering (DLS, (see supporting data), and in good agreement with the average diameter of $183 \mathrm{~nm}$ measured on 100 
220 individual dry particles by Atomic Force Microscopy (AFM, Figure 2A). Several reasons

221 motivated our choice for polyA, which is the main constituent of the walls of the colloidosomal

222 microcapsules. First, acrylic polymers are currently accepted by the U.S. Food and Drug

223 Administration for use in contact with food, according to the code of federal regulations title 21

224 [29]. Second, the emulsion polymerization process is performed in water in the absence of any

225 organic solvent. Third, at the alkaline $\mathrm{pH}$ of the midgut of $T . n i(\mathrm{pH} \sim 8.5)$ [30] the polymer is

226 dissolved in water, and the content of the capsule is released. However, at lower $\mathrm{pH}$ such as

227 those generally encountered in the environment, the polymer is insoluble in water, and the

228 envelope of colloïdosomal microcapsule is preserved. Indeed, the capsules are intact at slightly

229 acidic or neutral $\mathrm{pH}$ (Figure 2C), but dissolution of the polymeric capsule wall at $\mathrm{pH}=8.5$ is

230 observed in less than 15 seconds by optical microscopy, as shown in Figure 2D. Last, the glass

231 transition temperature $(\mathrm{Tg})$ of polyA, as measured by differential scanning calorimetry (see

232 supporting data), is only $65^{\circ} \mathrm{C}$. The Tg value corresponds to the temperature at which a polymer

233 switches from hard and glassy to soft and viscous. This low value favors the locking process

234 (fusion of the latex polymer particles in a continuous polymer shell). Once the latex was

235 prepared, $B$.t. bacterium and $\mathrm{NaCl}$ were added. The $B$. $t$. bacterium appeared in the form of an

236 ellipsoid of $2 \mu \mathrm{m}$ length and $1 \mu \mathrm{m}$ diameter, as measured by AFM (Figure 2B). The role of $\mathrm{NaCl}$

237 was to stabilize the emulsion against Ostwald ripening in the subsequent step. The chosen oil

238 phase was alimentary sunflower oil. Black iron oxide $\left(\mathrm{Fe}_{3} \mathrm{O}_{4}\right)$ nanoparticles $(1 \mathrm{~g} / \mathrm{L})$ were added

239 in the oil phase to serve as light absorbing material in the final formulation. Iron oxide

240 nanoparticles have been reported to be devoid of toxicity at low doses [31]. They exhibit a strong

241 absorption in the $300-900 \mathrm{~nm}$ region, with a broad maximum at $440 \mathrm{~nm}$, as measured by UV-

242 visible absorption spectroscopy. Upon mixing the aqueous phase (B) and the oil phase (C), a 
243 Pickering w/o emulsion was obtained (D). The latex nanoparticles have a surface energy which

244 is intermediate between oil and water, thus they position themselves at the interface between

245 water and oil. Upon adding ethanol, the latex particles within the aqueous droplet become

246 colloidally unstable. They coalesce to form a continuous shell of polymer, resulting in the

247 formation of a microcapsule. The dark grey capsules were separated from the oil phase via gentle

248 centrifugation. Separation from the oil phase was found to be necessary, as oil was found to be

249 toxic to the T. ni larvae, thus inducing false positive results (see below). The capsules had an

250 average diameter of 50 microns (Figures 2C, 2D). Notably, the gap between the mandibles

251 (measurement of inner structures) of first instar T. ni larvae was measured to ca. 110 microns,

252 thus large enough to allow the passage of the microparticles. Once separated from the

253 supernatant, the microparticles appeared as a free-flowing grey powder. Remarkably, the

254 fabrication of these capsules did not require any organic solvent and was entirely performed at

255 room temperature, which was necessary to maintain $B . t$. bioactivity. As negative control, 256 microcapsules containing lactose powder instead of $B$. $t$. were also prepared in the same fashion. 

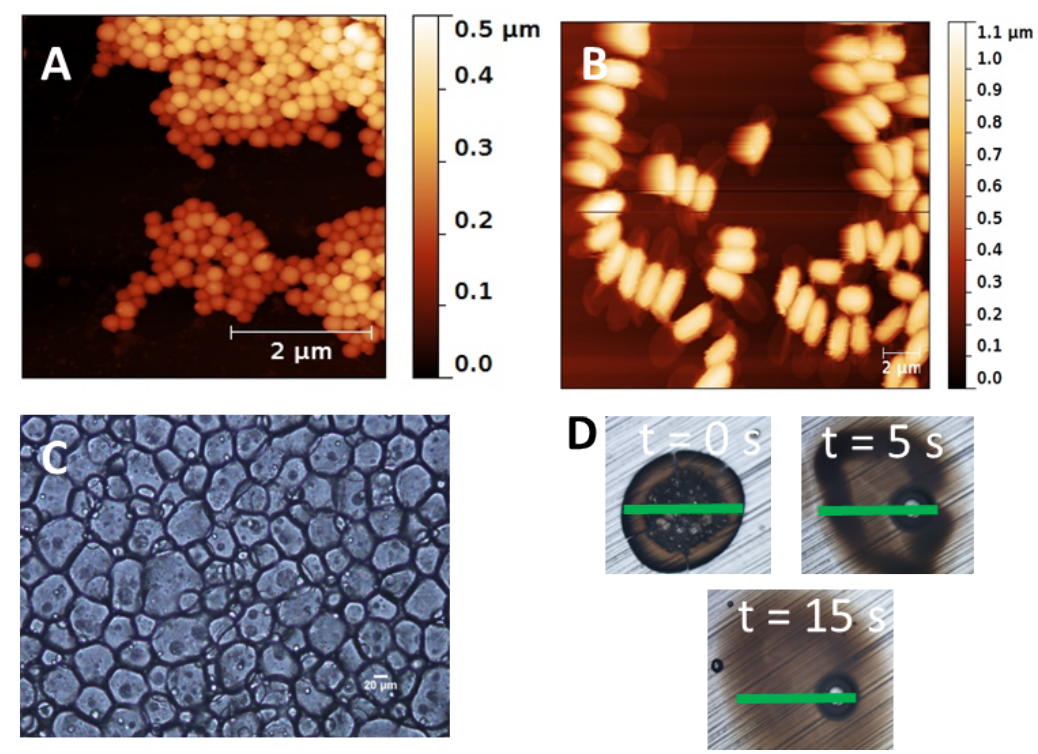

261 Figure 2. A) Latex of PolyA as observed by AFM. B) Strain of $B$. $t$., as observed by AFM. C) 262 Colloidosomal microcapsules containing the encapsulated $B$. $t$., as observed by optical microscopy (20X). D) Kinetics of dissolution of a microcapsule at $\mathrm{pH}=8.5$, as observed by optical microscopy $(10 \mathrm{X})$. The green bar $(50 \mu \mathrm{m})$ is set at the same location in each picture. 
In laboratory bioassays, larval mortality of $T$. $n i$ was $<10 \%$ for Control 1 (water) and 2 268 (iron nanoparticles). Acetonic powder of B. t. 407 caused $<14 \%$ larval mortality (Table 1) which 269 is expected because this $B . t$. serovar has no bioactivity on $T$. $n i$ [24]. Lactose powder caused 5.99.6\% larval mortality when formulated without oil, while it was $72-76 \%$ when formulated with

271 oil. Similarly, mortality caused by microencapsulated acetonic powder of B. t. 407 was much 272 higher when formulated with oil $(>75.5 \%)$ than in the absence of oil $(<28.6 \%)$. These results 273 demonstrate that except for oil, all other components present in the colloïdosome are innocuous 274 to $T$. $n i$ larvae. All further results are reported for colloïdosomes which are free of oil. By 275 contrast, when the microcapsule contained B. t. kurstaki HD-1 powder, ca. 100\% larval mortality

276 was observed, which was comparable to the mortality observed with non-encapsulated $B$. $t$. 277 kurstaki HD-1 powder. Our results demonstrate that the bioactivity of B. $t$. kurstaki HD-1 was 278 not significantly altered by the microencapsulation process. 


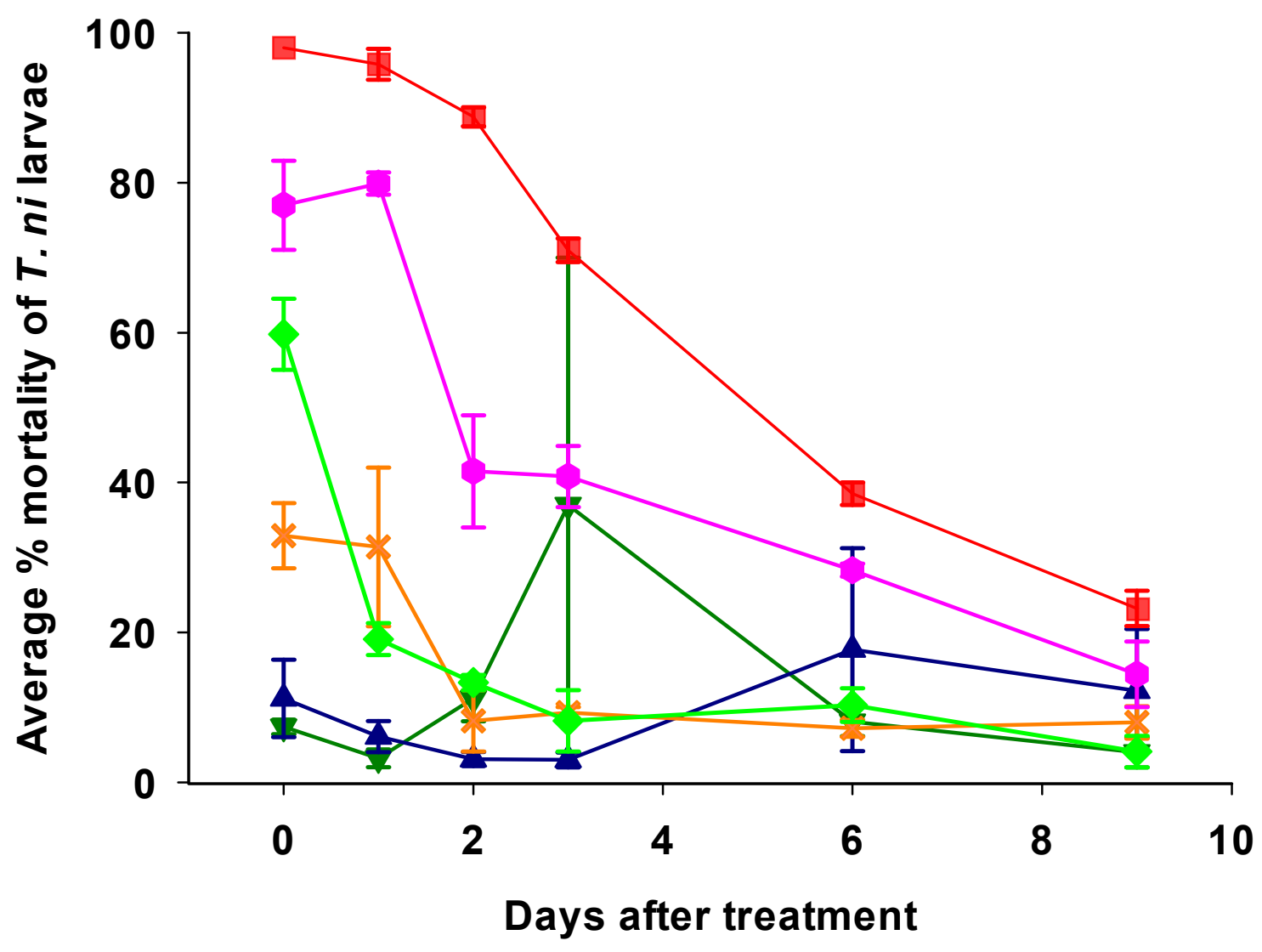

282

Figure 3. Persistence of bioactivity of $B$. $t$. formulations sprayed on potted cabbage plants in the field on 29 July 2014 (=day 0). Leaf disks were punctured and brought in the laboratory where they were assayed on $T$. $n i$ larvae $(n=50$ per treatment, 2 repeat experiments, error bar: standard deviation). 
287 Table 1. Mortality of $T$. $n i$ larvae following treatment with various $B$. $t$. formulations in the 288 laboratory.

\begin{tabular}{|c|c|c|c|c|}
\hline \multirow[b]{2}{*}{ Treatment } & \multicolumn{2}{|c|}{ Bioassay 1} & \multicolumn{2}{|c|}{ Bioassay 2} \\
\hline & $\begin{array}{l}\text { \# larvae } \\
\text { assayed }\end{array}$ & $\begin{array}{l}\text { \% larval } \\
\text { mortality }\end{array}$ & $\begin{array}{l}\text { \# larvae } \\
\text { assayed }\end{array}$ & $\begin{array}{l}\text { \% larval } \\
\text { mortality }\end{array}$ \\
\hline Control 1 (water) & 51 & 0.0 & 53 & 7.5 \\
\hline Control 2 (Iron nanoparticules) & 50 & 2.0 & 51 & 9.8 \\
\hline B. t. 407 & 50 & 0.0 & 50 & 14.0 \\
\hline B. t. 407 (microencapsulated, no oil) & 50 & 0.0 & 49 & 28.6 \\
\hline B. t. 407 (microencapsulated, with oil) & 53 & 75.5 & 51 & 92.2 \\
\hline Lactose & 50 & 4.0 & 50 & 14.0 \\
\hline Lactose (microencapsulated, no oil) & 51 & 5.9 & 52 & 9.6 \\
\hline Lactose (microencapsulated, with oil) & 50 & 76.0 & 50 & 72.0 \\
\hline B. t. kurstaki HD-1 & 50 & 100.0 & 50 & 100 \\
\hline B. t. kurstaki HD-1 (microencapsulated, no oil) & 49 & 75.5 & 48 & 97.9 \\
\hline B. t. kurstaki HD-1 (microencapsulated, with oil) & 49 & 100.0 & 50 & 100 \\
\hline
\end{tabular}
289 


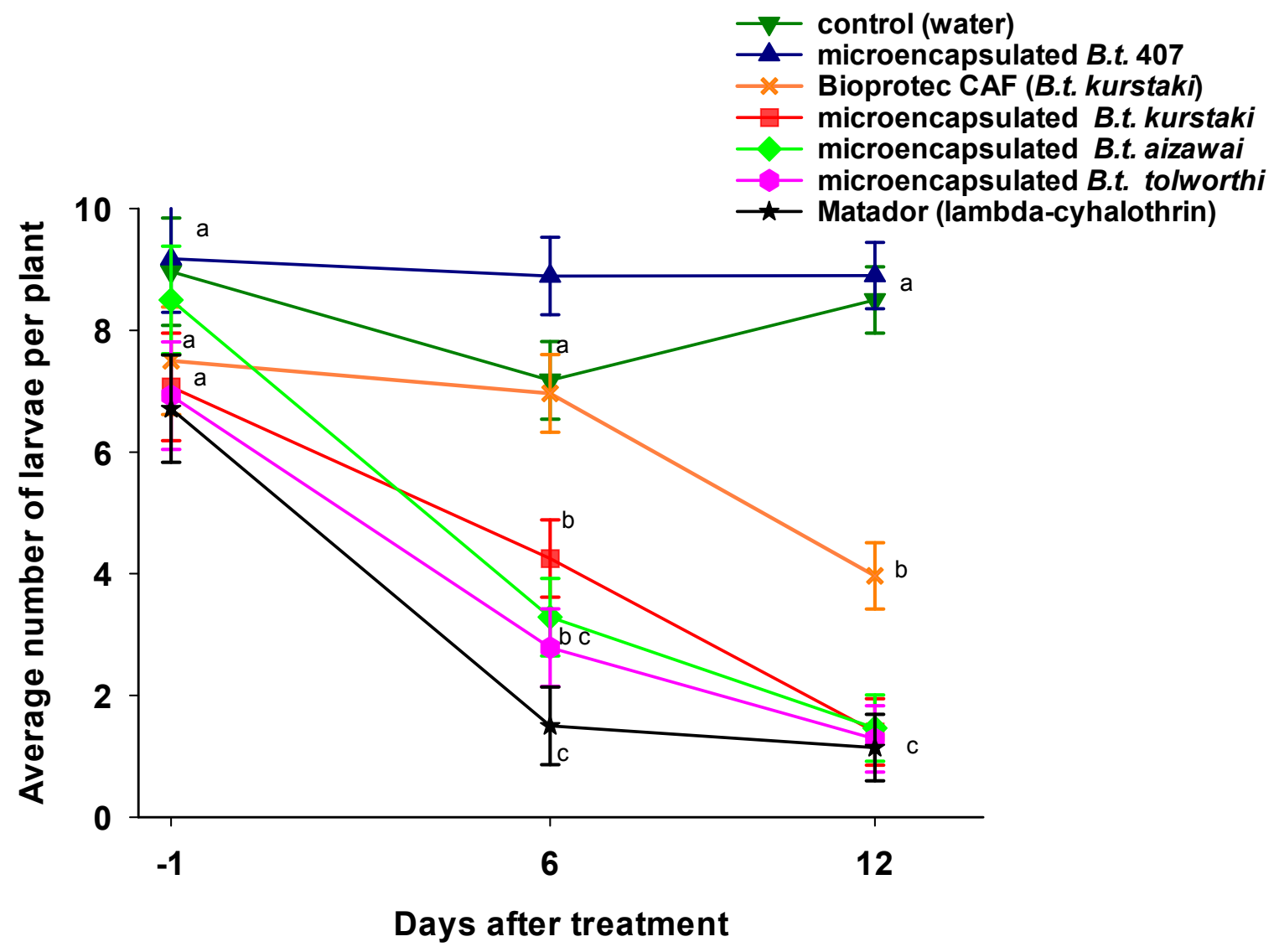

Figure 4. Average number of lepidopteran (all species and larval stages pooled), larvae per cabbage plant in the field. A first evaluation of larval populations was done one day before treatment, i.e. 27 August 2014. Treatments were done on 28 August and 5 September 2014. For a given number of days after treatment, numbers flanked by the different letters are significantly different at $\mathrm{p}<0.05$ (Tukey HSD). 
301 Table 2. Meteorological conditions prevailing during A) persistence and B) field tests with $B$. $t$.

302 formulations at L'Acadie (Qc, Canada) in 2014.

303 A) Persistence test, treatment of July 29, 2014 (=day 0)

\begin{tabular}{ccccccc}
\hline $\begin{array}{c}\text { Days } \\
\text { after } \\
\text { treatment }\end{array}$ & $\begin{array}{c}\text { Maximum } \\
\text { temperature } \\
\left({ }^{\circ} \mathrm{C}\right)\end{array}$ & $\begin{array}{c}\text { Minimum } \\
\text { temperature } \\
\left({ }^{\circ} \mathrm{C}\right)\end{array}$ & $\begin{array}{c}\text { Average } \\
\text { temperature } \\
\left({ }^{\circ} \mathrm{C}\right)\end{array}$ & $\begin{array}{c}\text { Relative } \\
\text { humidity } \\
(\%)\end{array}$ & $\begin{array}{c}\text { Precipitations } \\
(\mathrm{mm})\end{array}$ & $\begin{array}{c}\text { Solar } \\
\text { radiation } \\
\left(\mathrm{MJ} / \mathrm{m}^{2}\right)\end{array}$ \\
\hline 0 & 20.4 & 11.6 & 15.9 & 81.4 & 0.0 & 23.9 \\
1 & 23.7 & 10.7 & 17.9 & 79.8 & 0.0 & 25.2 \\
2 & 22.0 & 13.1 & 17.4 & 88.2 & 8.8 & 18.2 \\
3 & 25.8 & 13.6 & 20.1 & 81.6 & 0.0 & 21.3 \\
4 & 27.3 & 15.5 & 20.6 & 88.3 & 0.0 & 17.3 \\
5 & 27.6 & 14.1 & 21.1 & 80.2 & 0.0 & 24.3 \\
6 & 27.4 & 16.3 & 21.5 & 79.9 & 0.0 & 20.7 \\
7 & 25.5 & 14.7 & 20.2 & 84.7 & 0.0 & 19.4 \\
8 & 25.1 & 15.0 & 19.8 & 68.2 & 2.2 & 24.4 \\
9 & 23.3 & 14.3 & 18.0 & 82.5 & 0.0 & 18.3 \\
\hline
\end{tabular}

304

305 B) Field test, treatment of August 28, 2014 (=day 0)

\begin{tabular}{ccccccc}
\hline $\begin{array}{c}\text { Days } \\
\text { after } \\
\text { treatment }\end{array}$ & $\begin{array}{c}\text { Maximum } \\
\text { temperature } \\
\left({ }^{\circ} \mathrm{C}\right)\end{array}$ & $\begin{array}{c}\text { Minimum } \\
\text { temperature } \\
\left({ }^{\circ} \mathrm{C}\right)\end{array}$ & $\begin{array}{c}\text { Average } \\
\text { temperature } \\
\left({ }^{\circ} \mathrm{C}\right)\end{array}$ & $\begin{array}{c}\text { Relative } \\
\text { humidity } \\
(\%)\end{array}$ & $\begin{array}{c}\text { Precipitations } \\
(\mathrm{mm})\end{array}$ & $\begin{array}{c}\text { Solar } \\
\text { radiation } \\
\left(\mathrm{MJ} / \mathrm{m}^{2}\right)\end{array}$ \\
\hline 0 & 20.7 & 11.8 & 17.3 & 74.7 & 0.0 & 13.2 \\
1 & 21.7 & 9.8 & 16.1 & 78.1 & 0.0 & 21.6 \\
2 & 25.0 & 12.4 & 20.3 & 77.3 & 0.0 & 18.1 \\
3 & 23.4 & 18.8 & 21.2 & 92.7 & 12.6 & 4.9 \\
4 & 26.4 & 17.2 & 21.5 & 87.2 & 0.0 & 16.7 \\
5 & 28.7 & 17.6 & 22.5 & 84.9 & 1.2 & 14.0 \\
6 & 24.6 & 16.1 & 19.9 & 79.0 & 1.0 & 20.0 \\
7 & 27.2 & 13.0 & 20.0 & 80.6 & 0.0 & 19.4 \\
8 & 28.6 & 17.4 & 23.5 & 81.0 & 2.0 & 15.8 \\
9 & 24.3 & 14.2 & 20.2 & 85.4 & 4.4 & 5.1 \\
10 & 21.6 & 8.2 & 14.9 & 78.5 & 1.1 & 18.6 \\
11 & 24.0 & 8.6 & 16.8 & 76.8 & 0.0 & 18.2 \\
12 & 23.0 & 11.8 & 17.5 & 69.6 & 0.0 & 19.6 \\
\hline
\end{tabular}


307

308

309

310

311

312

313

314

315

316

317

318

319

320

321

322

323

324

325

326

327

328

329

\subsection{Field trials and persistence of the colloidosomal $B$. $t$. formulation}

In the persistence trial, \% larval mortality was low for the control (water) and for $B$.t. 407 (microencapsulated), averaging $10.3 \%$ (with an outlier of $37 \%$ on the third day after treatment) (Figure 3). Immediately after treatment, the highest larval mortality $(97.9 \%)$ was observed for $B$.

t. kurstaki (microencapsulated). With larval mortality of 95.8, 88.7, 70.9, 38.4 and 23.2\% determined respectively after 1, 2, 3,6 and 9 days, the bioactivity of that treatment remained consistently higher than any others. The second best persistence was observed for B. $t$. tolworthi (microencapsulated), with 77.0, 79.9, 41.4, 40.8, 28.3, and $14.3 \%$ larval mortality at $0+, 1,2,3$, 6 and 9 days after treatment respectively. The Bioprotec CAF treatment (non-encapsulated B. $t$. kurstaki) caused 32.9 and $31.4 \%$ larval mortality immediately and 1 day after treatment, respectively, while it caused $<10 \%$ larval mortality from day 3 to day 9 . Thus, the bioactivity of B. $t$. is significantly extended by microencapsulation.

One day before treatment (i.e., 27 August 2014) in the field trial, all larval populations of lepidopteran pests consistently averaged ca. 8 larvae per plant (Figure 4). Throughout the field test, larval populations for the control (water) and for B. t. 407 (microencapsulated) were not significantly different and ranged from 7.2 to 9 larvae per plant. Six days after treatments (i.e., 3 September 2014), larval populations in the commercial formulation (Bioprotec CAF) were not significantly different from the control (water) and B. t. 407. Larval populations for the microencapsulated B. t. kurstaki, B. t. aizawai and B. t. tolworthi were lower than for control experiments, ranging from 2.8-4.2 larvae per plant, while lambda-cyhalothrin was significantly lower than all other treatments (1.5 larvae per plant). Twelve days after treatments (i.e., 9 September 2014), there were no significant differences between lambda-cyhalothrin, microencapsulated B.t. kurstaki, B. t. aizawai and B. t. tolworthi (all having ca. 1.4 larvae per 
330 plant), while there was significant a difference between the latter treatment and Bioprotec CAF

331 (ca. 4 larvae per plant). Thus, the microencapsulated $B$. $t$. formulations are as efficient as the

332 broad range pyrethroid insecticide Matador, and significantly more efficient than non333 encapsulated $B$. $t$. formulations.

\section{Conclusions}

In this paper, we demonstrated that the Pickering emulsion process is an efficient process

for the encapsulation of biopesticides using only innocuous components. Thus, opaque $B$. $t$.loaded colloidosomes were shown to maintain the bioactivity of $B$. $t$., even when exposed to solar illumination. These colloidosomes included a $\mathrm{pH}$-triggered release mechanism in order to deliver the payload in the slightly alkaline environment of lepidopteran midguts. In theory, this pH-triggering mechanism would preclude unintended impacts upon non-target organisms having rather acidic digestive systems. Field-tests demonstrated that the microencapsulation process confer extended B. $t$. bioactivity. Based on these positive results, we believe that the use of

345 colloïdosomal microencapsulated formulations is a promising strategy for the development of 346 environmentally acceptable pesticides for agriculture systems.

\section{Conflicts of interest}


352 We thank Guy Boivin (Agriculture and Agri-Food Canada, Saint-Jean-sur-Richelieu, QC,

353 Canada) for T. ni specimens and Michel Brouillard, Jérémie Côté, Corentin Moreau and Vicky

354 Lachance for technical input. We thank Jean-François Landry, Ottawa Research and

355 Development Centre (Agriculture and Agri-Food Canada) for help in measuring structures of the 356 head of T. ni larvae.

357

358

359

\section{References}

360

361

362

363

364

365

366

367

368

369

370

371

372 [6]

[1] H. Höfte, H.R. Whiteley, Insecticidal crystal proteins of Bacillus thuringiensis, Microbiol. Rev. 53 (1989) 242-255.

[2] Research and markets, Worldwide summary biopesticides market 2013, 2013.

http://www.researchandmarkets.com/research/xghmtf/worldwide_summary, 2013 (accessed 10.02.2016).

[3] X. Zhou, C. She, H. Liu, Loading and light degradation characteristics of Bt toxin on nanogoethite: A potential material for controlling the environmental risk of $B t$ toxin, J. Nanomater. 2015, (2015), 849693.

[4] A. Knowles, Recent developments of safer formulations of agrochemicals, Environmentalist, 28, (2008) 35-44.

[5] D.L. Wise, Handbook of Pharmaceutical Controlled Release Technology, CRC Press, New York, Basel, 2000.

6] G. Ma, Microencapsulation of protein drugs for drug delivery: Strategy, preparation, and 
applications, J. Control. Release. 193 (2014) 324-340.

374 [7] A. Murua, A. Portero, G. Orive, R.M. Hernández, M. de Castro, J.L. Pedraz, Cell microencapsulation technology: Towards clinical application, J. Control. Release. 132 (2008) 76-83.

[8] I.Y. Kim, P.L. Pusey, Y. Zhao, S.S. Korban, H. Choi, K.K. Kim, Controlled release of Pantoea agglomerans E325 for biocontrol of fire blight disease of apple, J. Control. Release. 161 (2012) 109-115.

[9] C. Linder, A. Markus, Advances in the technology for controlled-release pesticide formulations, in: S. Benita (Ed.), Microencapsulation Methods and Industrial Applications, Second Ed., CRC Press, New York London, 2005: pp. 55-77.

[10] S. Boyetchko, E. Pedersen, Z. Punja, M. Reddy, Formulations of biopesticides, in: F.R.

[12] A. De, R. Bose, A. Kumar, S. Mozumdar, Targeted delivery of pesticides using biodegradable polymeric nanoparticles, Springer India, New Delhi, 2014.

[13] R.W. Behle, D.L. Compton, J.A. Kenar, D.I. Shapiro-Ilan, Improving formulations for biopesticides: Enhanced UV protection for beneficial microbes, J. ASTM Int. 8 (2011) 102793. 
394 [14] J.C. Côté, C. Vincent, K.H. Son, H.B. Bok, Persistence of insecticidal activity of novel

395 bio- encapsulated formulations of Bacillus thuringiensis var. kurstaki against

Choristoneura rosaceana [Lepidoptera : Tortricidae ], Phytoprotection. 82 (2011) 73-82.

397

398

399

400

401

402

403

404

405

406

407

408

409

410

411

412

413

414

[15] O.D. Velev, K. Furusawa, K. Nagayama, Assembly of latex particles by using emulsion droplets as templates. 1. Microstructured hollow spheres, Langmuir. 12 (1996) 23742384 .

[16] O.D. Velev, K. Furusawa, K. Nagayama, Assembly of latex particles by using emulsion droplets as templates. 2. Ball-like and composite aggregates, Langmuir. 12 (1996) 23852391.

[17] K.L. Thompson, S.P. Armes, J.R. Howse, S. Ebbens, I. Ahmad, J.H. Zaidi, D.W.York, J.A. Burdis, Covalently cross-linked colloidosomes, Macromolecules. 43 (2010) 1046610474.

[18] S.A.F. Bon, P.J. Colver, Pickering miniemulsion polymerization using laponite clay as a stabilizer, Langmuir. 23 (2007) 8316-8322.

[19] A.D. Dinsmore, M.F. Hsu, M.G. Nikolaides, M. Marquez, A.R. Bausch, D.A. Weitz, Colloidosomes: selectively permeable capsules composed of colloidal particles., Science . 298 (2002) 1006-1009.

[20] P.H.R. Keen, N.K.H. Slater, A.F. Routh, Encapsulation of yeast cells in colloidosomes., Langmuir. 28 (2012) 1169-74.

[21] P.H.R. Keen, N.K.H. Slater, A.F. Routh, Encapsulation of lactic acid bacteria in colloidosomes., Langmuir. 28 (2012) 16007-14. 
415 [22] T. Nomura, A.F. Routh, A novel method of fabrication of latex-stabilized water-core

416 colloidosomes at room temperature., Langmuir. 26 (2010) 18676-80.

417 [23] Agriculture and Agri-Food Canada, Crop Profile for Brassica Vegetables in Canada 2012, $418 \quad$ Agriculture Canada, Ottawa, 2012.

419

420

421

422

423

424

425

426

427

428

429

430

431

432

433

434

435

[24] A.E. Sheppard, A. Poehlein, P. Rosenstiel, H. Liesegang, H.Schulenburg, Complete Genome Sequence of Bacillus thuringiensis Strain 407 Cry-., Genome Announc. 1 (2013) e00158-12.

[25] G.S.A.B. Stewart, K. Johnstone, E. Hagelberg, D.E. Ellar, Commitment of bacterial spores to germinate. A measure of the trigger reaction., Biochem. J. 198 (1998) 101-106.

[26] H.T. Dulmage, J.A. Correa, A.J. Martinez, Coprecipitation with lactose as a means of recovering the sporte-crystal complex of Bacillus thuringiensis, J. Invertebr. Pathol. 15 (1970) 15-20.

[27] H.H. Shorey, R.L. Hale, Mass-Rearing of the Larvae of Nine Noctuid Species on a Simple Artificial Medium, J. Econ. Entomol. 58 (1965) 522-524.

[28] G. Bourgeois, D. Plouffe, G. Chouinard, N. Beaudry, D. Choquette, O. Carisse, J. DeEll, The apple Cipra network in Canada: using real-time weather information to forecast apple phenology, insects, diseases and physiological disorders, Acta Hortic. 803 (2008) 29-34.

[29] CFR - Code of Federal Regulations Title 21, http://www.accessdata.fda.gov/scripts/cdrh/cfdocs/cfCFR/CFRSearch.cfm?fr=177.1010 (accessed 10.02.2015).

[30] X. Wang, D.C. Kelly, Baculovirus replication: Uptake of Trichoplusia ni nuclear polyhedrosis virus particles by insect cells, J. Gen. Virol. 66 (1985) 541-550. 
436 [31] B. Samanta, H. Yan, N.O. Fischer, J. Shi, D.J. Jerry, V.M. Rotello, Protein-passivated

$437 \mathrm{Fe}_{3} \mathrm{O}_{4}$ nanoparticles: low toxicity and rapid heating for thermal therapy, J. Mater. Chem. $438 \quad 18(2008) 1204$. 